\title{
Potential cancer-related role of circadian gene TIMELESS suggested by expression profiling and in vitro analyses
}

Yingying Mao ${ }^{1,2}$, Alan Fu², Derek Leaderer ${ }^{2}$, Tongzhang Zheng ${ }^{2}$, Kun Chen ${ }^{1}$ and Yong Zhu ${ }^{2 *}$

\begin{abstract}
Background: The circadian clock and cell cycle are two global regulatory systems that have pervasive behavioral and physiological effects on eukaryotic cells, and both play a role in cancer development. Recent studies have indicated that the circadian and cell cycle regulator, TIMELESS, may serve as a molecular bridge between these two regulatory systems.

Methods: To assess the role of TIMELESS in tumorigenesis, we analyzed TIMELESS expression data from publically accessible online databases. A loss-of-function analysis was then performed using TIMELESS-targeting siRNA oligos followed by a whole-genome expression microarray and network analysis. We further tested the effect of TIMELESS down-regulation on cell proliferation rates of a breast and cervical cancer cell line, as suggested by the results of our network analysis.
\end{abstract}

Results: TIMELESS was found to be frequently overexpressed in different tumor types compared to normal controls. Elevated expression of TIMELESS was significantly associated with more advanced tumor stage and poorer breast cancer prognosis. We identified a cancer-relevant network of transcripts with altered expression following TIMELESS knockdown which contained many genes with known functions in cancer development and progression. Furthermore, we observed that TIMELESS knockdown significantly decreased cell proliferation rate.

Conclusions: Our results suggest a potential role for TIMELESS in tumorigenesis, which warrants further investigation of TIMELESS expression as a potential biomarker of cancer susceptibility and prognostic outcome.

Keywords: TIMELESS, Circadian gene, Cell cycle, Tumorigenesis, Expression profiling

\section{Background}

The circadian clock and cell cycle are two global regulatory systems that have pervasive effects on the behavior and physiology of eukaryotic cells. The 24-hour periodicity of the circadian rhythm, consisting of light and dark phases which coincide with the phases of the solar day, is maintained by a set of core circadian genes through a complex mechanism involving transcription-translational feedback loops $[1,2]$. The cell cycle is monitored by a sequence of molecular and biochemical events including a series of checkpoint mechanisms to ensure completion of

\footnotetext{
* Correspondence: yong.zhu@yale.edu

${ }^{2}$ Department of Environmental Health Sciences, Yale School of Public Health, New Haven, CT 06520, USA

Full list of author information is available at the end of the article
}

biochemical reactions unique to each phase of the cell cycle prior to initiation of subsequent phases $[3,4]$.

While these two regulatory systems involve distinct mechanisms, there is evidence that they are linked and interact at the gene, protein, and biochemical levels $[5,6]$. A recent study has indicated that one circadian regulator, TIMELESS, is also a core component of the cell cycle checkpoint system [7]. It regulates directly or indirectly the activity of autoregulatory components of the mammalian circadian core, including Clock, Per, and Cry proteins, associates with $\mathrm{S}$ phase replication checkpoint proteins Claspin and Tipin, and is required for the phosphorylation and activation of Chk1 by ATR and ATM-dependent Chk2-mediated signaling of DNA double strand breaks $[8,9]$.

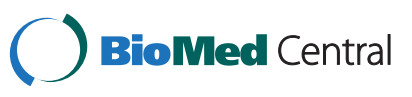


Although the connection between cancer and the cell cycle machinery that controls cell proliferation has been evident for some time, and there is mounting evidence to suggest that disruption of the circadian rhythm may increase susceptibility to certain malignancies [10-12], little is known about TIMELESS's role in tumorigenesis. Our previous case-control study demonstrated significant genetic and epigenetic associations of TIMELESS and breast cancer risk [13]. A recent study has also shown that higher levels of TIMELESS expression in colorectal cancer tissue is associated with TNM stages III-IV and microsatellite instability [14]. In contrast, findings from another study point to the down-regulation of TIMELESS in hepatocellular carcinomas [15].

In the current study, we report our findings from the expression profiling analysis of TIMELESS in different tumor types using publically available online tools and microarray datasets, and a loss-of-function analysis using TIMELESS-targeting siRNA oligos followed by a wholegenome expression microarray and network analysis. We also tested one of the potential roles of TIMELESS suggested by our network analysis using a MTS assay and observed that TIMELESS knockdown decreased the proliferation rate of MCF7 breast cancer cells.

\section{Methods}

\section{Data mining of TIMELESS expression in different tumor types}

To explore whether TIMELESS expression is altered in different cancer types, we first performed a comprehensive search using the Oncomine 4.4 online database (https://www.oncomine.org; accessed on September 7, 2011) [16] for expression array comparisons involving tissues drawn from cancer patients and healthy controls. The keywords used were: Gene: "TIMELESS"; Analysis Type: "Cancer vs. Normal Analysis". The search returned a total of 194 analyses conducted in 93 unique studies across various cancer types using different array platforms. Further details regarding tissue collection and the experimental protocol of each array are available in the Oncomine database, or from the original publications.

We then investigated whether aberrant TIMELESS expression was associated with tumor stage or prognostic outcome. We searched and analyzed publicly available microarray data sets containing tumor stage or clinical outcome information from the Gene Expression Omnibus (GEO) [17] and ArrayExpress databases (www.ebi.ac.uk/ arrayexpress; accessed on September 8, 2011). The cervical cancer data set (GEO accession \# GSE7803) contains gene expression data of normal cervical tissue, high-grade squamous intraepithelial lesions and invasive squamous cell carcinomas [18]. The ArrayExpress breast cancer data set (accession \# E-TABM-276) examined gene expression in malignant breast tumor tissue, adjacent tissue exhibiting cystic changes, adjacent normal breast tissue and tissue drawn from healthy controls [19]. The prostate cancer data set GSE8511 includes tissue from benign prostate and localized and metastatic prostate tumor tissues [20], and GSE21034 contains samples from normal adjacent benign prostate and primary and metastatic prostate tumor tissues [21]. GSE2034 examined the association between gene expression in tissues drawn from primary breast cancer patients and their clinical outcomes [22]. The GOBO online tool (Gene Expression-Based Outcome for Breast Cancer Online co.bmc.lu.se/gobo), designed for prognostic validation of genes in a pooled breast cancer data set comprising 1881 cases from 11 public microarray data sets, was used to validate our analysis of the GSE2034 breast cancer data set [23].

\section{Cell culture and treatments}

All experimental procedures were approved by the Institutional Review Board at Yale University and the National Cancer Institute. To determine TIMELESS's role in tumorigenesis, we then performed an in vitro loss-of-function analysis using TIMELESS-targeting siRNA oligos followed by a whole-genome expression microarray. Human HeLa cells (American Type Culture Collection, Manassas, VA) were maintained in Dulbecco's modified Eagle medium (Invitrogen, Carlsbad, CA) supplemented with $10 \%$ fetal bovine serum (Invitrogen) and $1 \%$ penicillin/streptomycin (Sigma-Aldrich, St. Louis, MO). Short interfering RNA (siRNA) oligonucleotides targeting exon 11 of TIMELESS (Ambion ID s17053; cat. no. 4392420) and a scrambled sequence negative control oligonucleotide were designed and manufactured by Ambion, Inc. (Ambion/Applied Biosystems). Each oligonucleotide was reverse-transfected in 12-well plates with $\sim 10,000$ cells/well at a final concentration of $10 \mathrm{nM}$ using the Lipofectamine RNAiMAX transfection reagent (Invitrogen).

\section{RNA isolation and quantification}

RNA was isolated using the RNA Mini Kit (Qiagen), with on-column DNA digestion, according to the protocols of the manufacturer for mammalian cells. RNA was quantified using a NanoDrop spectrophotometer (Thermo Scientific), and first-strand cDNA was synthesized using the AffinityScript cDNA Kit (Stratagene) with random ninemer primers. TIMELESS mRNA expression was measured by quantitative real-time PCR performed in duplicate using the Power SYBR Green PCR master mix (Applied Biosystems) and a standard thermal cycling procedure on an ABI 7500 instrument (Applied Biosystems). RNA quantity was normalized using HPRT1, and TIMELESS silencing was quantified using the $2^{-\Delta \Delta \mathrm{Ct}}$ method. 


\section{Genome-wide expression microarray}

Gene expression differences in normal HeLa cells and those with reduced TIMELESS levels were examined by whole genome microarray (Agilent, Inc., $44 \mathrm{~K}$ chip, performed by MoGene, LC). RNA was isolated from biological replicates of each treatment condition (TIMELESS-targeting or scrambled negative control). Gene expression fold changes in TIMELESS knockdown cells relative to the mock siRNA-treated negative control were determined for each replicate. Samples with inadequate signal intensity (i.e., intensity $<50$ in both the Cy3 and Cy5 channels), and transcripts with adjusted $P$-values greater than 0.05 in either biological replicate were discarded. To further reduce the number of false positive observations, and to enrich for biologically relevant expression changes, the remaining transcripts were defined as significantly differentially expressed only if they displayed a mean fold change in expression of at least $|2|$.

\section{Pathway-based network analysis}

We then interrogated the differentially expressed transcripts for network and functional interrelatedness using the Ingenuity Pathway Analysis software tool (Ingenuity Systems; www.ingenuity.com). The software uses an extensive database of functional interactions which are drawn from peer-reviewed publications and are manually maintained [24]. P-values for individual networks were obtained by comparing the likelihood of obtaining the same number of transcripts or greater in a random gene set as are actually present in the input set (i.e., the set of genes differentially expressed following TIMELESS knockdown) using a Fisher's exact test, based on the hypergeometric distribution. Our microarray data were uploaded to the Gene Expression Omnibus [17] database (www.ncbi.nlm.nih.gov/ projects/geo/; accession \# pending). The differential expression of several genes detected by the microarray was assessed and confirmed by quantitative real-time PCR. The primers used were designed in house and the sequences are provided in Additional file 1: Table S1.

\section{Cell proliferation assay}

The results from our network analysis suggested us to further investigate TIMELESS's potential role in cellular growth and proliferation. HeLa and MCF7 cells (American Type Culture Collection) were reverse transfected with siRNA oligos targeting TIMELESS and a scrambled sequence negative control in 96-well plates using the Lipofectamine RNAiMAX transfection reagent (Invitrogen). Cell proliferation was analyzed in triplicate at baseline, 24 hours, 48 hours, 72 hours, and 96 hours using the CellTiter $96^{\circ}$ AQueous One Solution Cell Proliferation Assay (MTS) kit (Promega Corporation, Madison, WI) and the absorbance was measured using an Epoch microplate spectrophotometer (BioTek, Winooski, VT).

\section{Statistical analyses}

Statistical analyses were performed using the SAS statistical software, version 9.2 (SAS Institute). Student t-tests and one-way ANOVA were applied to calculate differences in TIMELESS expression across different tumor stages, as well as differences in cell proliferation rate. The log-rank test was used to estimate the differences in survival between cancer patients with differing levels of TIMELESS expression. Due to the multiple comparisons inherent in our microarray analysis, adjustments were made to control for false discoveries using the Benjamini-Hochberg method, as previously described, to obtain a false discovery rate-adjusted $P$-value for each observation (referred to as the $Q$-value) [25].

\section{Results}

\section{Overexpression of TIMELESS in different types of} tumor tissues

Searching for "TIMELESS" expression in "cancer vs. normal" tissues in the Oncomine database returned a total of 194 analyses from 93 unique studies across various cancer types. 32 analyses in 20 unique studies were identified as statistically significant with $P$-values $<0.01$ and fold change $\geq|2|$. 31 out of 32 analyses exhibited increased TIMELESS expression in tumor relative to normal tissues while only one showed decreased expression (Additional file 1: Table S2). A volcano plot was generated using $-\log _{10}$ transformed $P$-values and the fold change of TIMELESS expression in tumor versus normal tissues extracted from each analysis. The size of each circle is proportional to the size of the analysis it corresponds to (Figure 1A). The plot indicates that TIMELESS expression is frequently elevated in tumor relative to normal tissues across multiple cancer types.

\section{Increased TIMELESS expression is associated with more advanced tumor stage and poorer breast cancer prognosis}

To investigate whether TIMELESS expression is associated with tumor stage and clinical outcome, we analyzed five publicly available microarray data sets extracted from the GEO and ArrayExpress online databases: GSE7803 (cervical cancer), GSE21034 (prostate cancer), GSE8511 (prostate cancer), GSE2034 (breast cancer), and E-TABM276 (breast cancer). We observed that TIMELESS expression in invasive cervical cancer tissue was significantly higher than in normal tissue $(P<0.001)$ and preinvasive cervical cancer tissue $(P<0.001)$ (Figure $1 B)$. In the breast cancer study E-TABM-276, TIMELESS expression in breast tissue from healthy controls was significantly lower than in invasive carcinomas $(P<0.001)$ or tissues exhibiting cystic changes $(P<0.05)$. Likewise, TIMELESS expression in adjacent normal breast tissues was significantly lower than in either invasive carcinomas or tissues with 


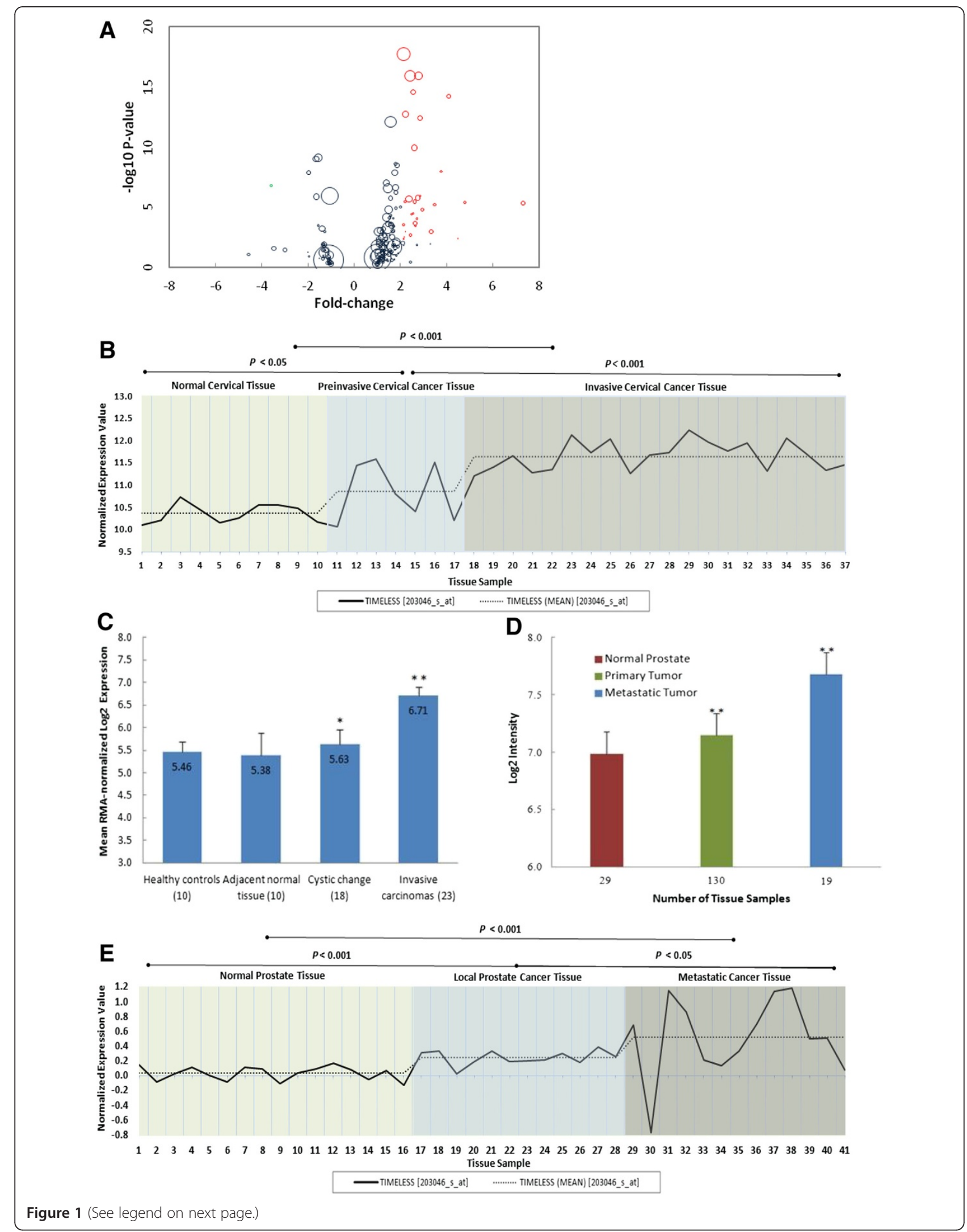


(See figure on previous page.)

Figure 1 Microarray data mining of TIMELESS expression in different tumor types. (A) TIMELESS expression in tumor tissues relative to controls from the Oncomine database. 31 out of 32 analyses showed higher TIMELESS expression while 1 analysis found lower TIMELESS expression. Analyses exhibiting $P$-values $<0.01$ and fold-change values $\geq|2|$ are marked in red and green respectively. The size of each circle is scaled by the sample size of the corresponding analysis. (B) TIMELESS expression in cervical cancer tissue versus preinvasive and normal tissue. Expression of TIMELESS in invasive cervical cancer tissues is significantly higher than in either normal or preinvasive tumor tissues. The original array data are from the Gene Expression Omnibus (accession \# GSE7803). (C) TIMELESS expression in breast tumor, adjacent tissues and tissues from healthy controls. TIMELESS expression in breast tissue from healthy controls and adjacent normal tissue was significantly lower than in invasive carcinomas or tissues exhibiting nonproliferative change (cystic change). Original array data is from the ArrayExpress database (accession \# E-TABM-276). (D) and (E) TIMELESS expression in prostate tumor and normal tissues. In normal prostate tissue, TIMELESS expression is significantly lower than in primary prostate tumor and metastatic tumor tissues. Metastatic tumor tissue exhibited the highest TIMELESS expression level compared to the other two groups. Original array data are from the Gene Expression Omnibus database (accession \#'s GSE21034 and GSE8511).

cystic changes $(P<0.001$ and $P<0.05$, respectively $)$ (Figure 1C). Similarly, in both of the two prostate cancer studies, significantly increased TIMELESS expression was observed in metastatic tumor tissue compared to primary prostate tumor tissue and benign tissue (Figure 1D and E).
Analyzing the lymph node-negative breast cancer data set of GSE2034, we found that patients with lower TIMELESS expression levels were more likely to have a higher rate of distant metastasis-free survival (DMFS) $(P<0.05)$. Interrogating TIMELESS expression using the GOBO database revealed similar results: increased
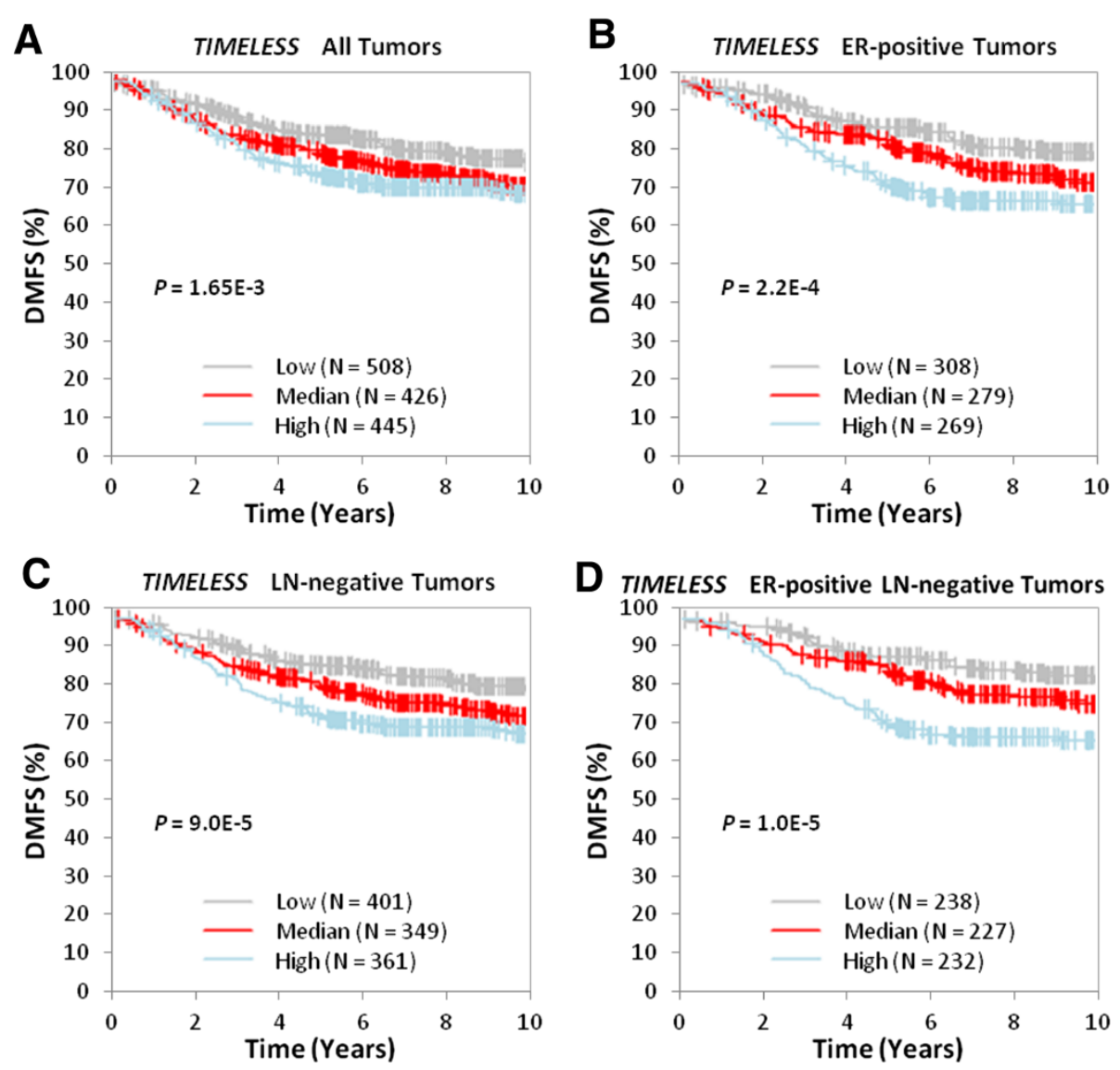

Figure 2 Kaplan-Meier survival analysis of TIMELESS expression using the GOBO online tool, which comprises of pooled data from 1881 breast cancer cases from 11 public data sets. Samples were stratified into tertiles based on TIMELESS expression level. The log-rank test was performed in all tumor samples as well as in different tumor subtypes using distant metastasis-free survival (DMFS) as the endpoint. High TIMELESS expression is significantly associated with lower DMFS over time among (A) all cases regardless of tumor ER- and LN-positivity $(P=1.65 \mathrm{E}-3)$, (B) cases with ER-positive tumors $(P=2.20 \mathrm{E}-4)$, (C) cases with $\mathrm{LN}$-negative tumors $(P=9.00 \mathrm{E}-5)$, and (D) cases with ER-positive and LN-negative tumors $(P=1.00 \mathrm{E}-5)$. 
TIMELESS expression was associated with lower DMFS rate not only in the general breast tumor population $(P<0.005)$, but also in tumor subtypes, including lymph node-negative $(P<0.001)$, ER-positive $(P<0.001)$, and lymph node- negative ER-positive $(\mathrm{P}<0.001)$ breast tumors (Figure 2).

\section{Cancer-relevant network formed by TIMELESS-influenced genes}

To explore TIMELESS's potential functional significance in regulating cancer-relevant gene networks, we performed a loss-of-function analysis using TIMELESStargeting siRNA oligos, followed by a whole genome expression microarray and subsequent network analysis. Prior to the microarray, TIMELESS knockdown was confirmed using quantitative RT-PCR. TIMELESS mRNA levels were reduced by more than $90 \%$ following knockdown $(P<0.01)$ (Additional file 2: Figure $S 1)$. In the array, 660 transcripts fit our significance criteria for differential expression following TIMELESS knockdown $(Q<0.05$ and mean fold change $\geq|2|$ ). Validation of differential expression was performed on nine genes using quantitative realtime PCR (Additional file 2: Figure S2). This gene set was examined for functional interrelatedness using the Ingenuity Pathway Analysis software tool. Cancer was identified as the top disease significantly associated with the input gene set, while cellular movement, development, and growth and proliferation were identified as the top three molecular and cellular functions.

Thirteen functional networks were identified as being significantly associated with the input gene set $(P<1.0 \mathrm{E}-10)$, the majority of which are cancer-related (Additional file 1: Table S3). The top functional network $(P=1.0 \mathrm{E}-32$, Figure 3) formed by TIMELESS-affected genes was defined as having relevance for "cellular movement, immune cell trafficking, [and] gene expression". Every one of the twenty-six genes within this top network has been reported to be involved in carcinogenesis or tumor progression. Among them, CXCL1 [26], EDN1 [27], EPAS1 [28,29], GDP15 [30,31], IL8 [32,33], KRT17 [34,35],

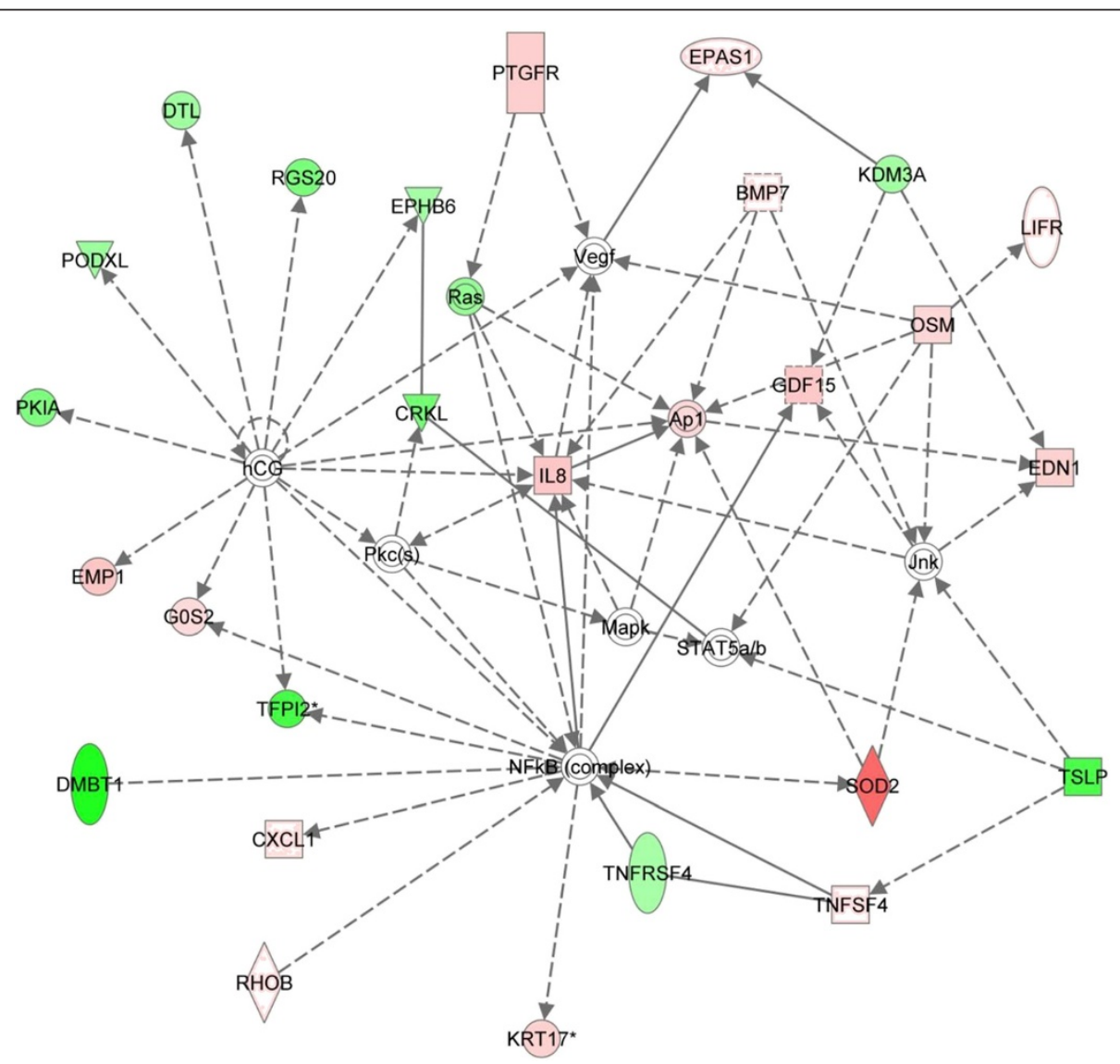

Figure 3 The IPA-generated network most significantly associated with genes affected by TIMELESS knockdown. According to the Ingenuity Pathway Analysis tool, the network is relevant to "cellular movement, immune cell trafficking, [and] gene expression". Transcripts that were upregulated following TIMELESS knockdown are shaded in red, while transcripts that were downregulated are shaded in green, with color intensity signifying the relative magnitude of change. Each interaction is supported by at least one literature reference identified in the Ingenuity Pathway Knowledge Base, with solid lines representing direct interactions, and dashed lines representing indirect interactions. 
Table 1 Molecules in the top $(P=1.0 E-32)$ network of genes differentially expressed following TIMELESS knockdown

\begin{tabular}{|c|c|c|c|c|}
\hline Symbol & RefSeq & Description & Fold change & Q-Value \\
\hline BMP7 & AL567265 & Growth factor, may play a role in early development & 2.41 & $5.2 \mathrm{E}-05$ \\
\hline$C R K L$ & NM_005207 & $\begin{array}{l}\text { Activates the RAS and JUN kinase signaling pathways } \\
\text { and transform fibroblast in RAS-dependent fashion, } \\
\text { candidate oncogene }\end{array}$ & -3.04 & $3.3 \mathrm{E}-06$ \\
\hline CXCL1 & NM_001511 & $\begin{array}{l}\text { Chemokine (C-X-C motif) ligand 1, regulates cell } \\
\text { trafficking }\end{array}$ & 2.10 & $1.4 \mathrm{E}-04$ \\
\hline DMBT1 & NM_007329 & $\begin{array}{l}\text { Plays a role in the interaction of tumor cells and the } \\
\text { immune system, candidate tumor suppressor }\end{array}$ & -5.26 & $1.3 \mathrm{E}-12$ \\
\hline$D T L$ & NM_016448 & $\begin{array}{l}\text { Denticleless homolog (Drosophila), required for cell } \\
\text { cycle control, DNA damage response and translesion } \\
\text { DNA sythesis }\end{array}$ & -2.34 & $2.0 \mathrm{E}-11$ \\
\hline EDN1 & NM_001955 & $\begin{array}{l}\text { Endothelin 1, growth factor, involved in tumor } \\
\text { progression }\end{array}$ & 4.26 & $5.8 \mathrm{E}-32$ \\
\hline EMP1 & BC017854 & Endothelia membrane protein 1 & 5.33 & 7.1E-13 \\
\hline EPAS1 & NM_001430 & $\begin{array}{l}\text { Endothelia PAS domain protein 1, transcription } \\
\text { factor, involved in the induction of genes regulated } \\
\text { by oxygen }\end{array}$ & 3.21 & $6.7 \mathrm{E}-11$ \\
\hline EPHB6 & NM_004445 & $\begin{array}{l}\text { EPH receptor B6, modulates cell adheson and } \\
\text { migration, mediates numerous developmental } \\
\text { processes, particularly in the nervous system. }\end{array}$ & -2.62 & $2.9 \mathrm{E}-05$ \\
\hline GOS2 & NM_015714 & G0/G1 switch regulatory protein 2, potential oncogene & 3.37 & 3.8E-09 \\
\hline GDF15 & NM_004864 & $\begin{array}{l}\text { Growth differentiation factor } 15, \text { member of the } \\
\text { transforming growth factor-beta superfamily, } \\
\text { regulates tissue differentiation and maintenance }\end{array}$ & 4.49 & $3.5 \mathrm{E}-12$ \\
\hline 148 & NM_000584 & $\begin{array}{l}\text { Interleukin 8, cytokine, inhibits the proliferation of } \\
\text { tumor cells }\end{array}$ & 5.10 & $1.7 \mathrm{E}-11$ \\
\hline KDM3A & NM_018433 & $\begin{array}{l}\text { May play a role in hormone-dependent transcription } \\
\text { acivation and histone code, involved in spermatogenesis } \\
\text { and obesity resistance }\end{array}$ & -2.13 & $1.5 \mathrm{E}-08$ \\
\hline KRT17 & NM_000422 & $\begin{array}{l}\text { Type I intermediate filament chain keratin } 17, \text { may be } \\
\text { a marker for basal cell differentiation in complex epithelia }\end{array}$ & 3.45 & 1.1E-07 \\
\hline LIFR & NM_002310 & $\begin{array}{l}\text { Leukemia inhibitory factor which is involved in cellular } \\
\text { differentiation, proliferation and survival }\end{array}$ & 2.77 & 2.7E-11 \\
\hline OSM & NM_020530 & Cytokine, inhibits the proliferation of a number cell lines & 3.23 & $1.5 \mathrm{E}-06$ \\
\hline PKIA & NM_006823 & Protein kinase inhibitor alpha & -3.30 & 7.2E-09 \\
\hline PODXL & NM_005397 & $\begin{array}{l}\text { Podocalyxin-like, involved in regulation of both adhesion } \\
\text { and cell morphology and cancer progression }\end{array}$ & -2.47 & $3.5 \mathrm{E}-06$ \\
\hline PTGFR & NM_000959 & Prostaglandin F receptor & 5.31 & 1.1E-08 \\
\hline RGS20 & NM_170587 & $\begin{array}{l}\text { Regulation of G-protein signaling } 20 \text {, accelarate transit } \\
\text { through the cycle of GTP binding and hydrolysis and } \\
\text { thereby accelerate signaling kinetics and termination }\end{array}$ & -3.34 & $3.4 \mathrm{E}-08$ \\
\hline$R H O B$ & NM_004040 & $\begin{array}{l}\text { Mediates apoptosis in neo plastically transformed cells } \\
\text { after DNA damage, affects cell adhesion and growth } \\
\text { factor signaling in transformed cells, involved in } \\
\text { intracellular protein trafficking of a number of proteins }\end{array}$ & 2.16 & $1.2 \mathrm{E}-04$ \\
\hline SOD2 & BC016934 & $\begin{array}{l}\text { Member of the iron/manganese superoxide dismutase } \\
\text { family potential tumor suppressor }\end{array}$ & 15.90 & $2.1 \mathrm{E}-14$ \\
\hline TFPI2 & ENST00000222543 & $\begin{array}{l}\text { Tissue factor pathway inhibitor } 2 \text {, may play a role in } \\
\text { the regulation of plasmin-mediated matrix remodeling }\end{array}$ & -5.19 & $4.9 E-12$ \\
\hline TNFRSF4 & NM_003327 & $\begin{array}{l}\text { Tumor necrosis factor receptor superfamily, member } 4 \text {, } \\
\text { may suppresses apoptosis, plays a role in T cells-dependent } \\
\text { B cell proliferation and differentiation }\end{array}$ & -2.09 & 8.6E-03 \\
\hline
\end{tabular}


Table 1 Molecules in the top $(P=1.0 E-32)$ network of genes differentially expressed following TIMELESS knockdown (Continued)

\begin{tabular}{lll}
\hline TNFSF4 NM_003326 & $\begin{array}{l}\text { Tumor necrosis factor (ligand) superfamily, member 4, } \\
\text { directly mediates adhesion of activated T cells to } \\
\text { vasular endothelial cells }\end{array}$ \\
TSLP NM_033035 & $\begin{array}{l}\text { Thymic stromal lymphopoietin, induces release of T } \\
\text { cell-attracting chemokines from monocytes and } \\
\text { enhances the maturation of CD11c(+) dendtritic cells }\end{array}$ \\
\hline
\end{tabular}

CRKL [36,37], DTL [38], PTGFR [39], KDM3A [40], PODXL [41], RGS20 [42], and TSLP [43] are observed to be frequently overexpressed in cancer cells and are suggested to be involved in cancer development, tumor progression or poorer prognostic outcome. In contrast, SOD2 [44,45], RHOB [46,47], GOS2 [48], EMP1 [49], TNFRSF4 [50], TNFSF4 [51], DMBT1 [52,53], LIFR [54], TFPI2 [55], and EPHB6 [56] are frequently down-regulated in cancer and may be associated with tumor suppression or favorable prognostic outcome. A summary of the genes in this network, along with a brief description of relevant functions, $Q$-values and fold changes following TIMELESS knockdown, is presented in Table 1.

\section{TIMELESS knockdown decreases breast cancer cell proliferation rate}

As suggested by the findings of our network analysis, we tested TIMELESSs potential role in cellular growth and proliferation using a MTS assay. As shown in Figure 4, transfection with TIMELESS-targeting siRNA oligos significantly decreased MCF7 cell growth compared to untreated MCF7 cells $(P<0.05)$ and negative control cells $(P<0.05)$. A similar trend was observed with HeLa cells, but only a slight, yet not statistically significant, decrease in proliferation rate was observed compared to negative control cells $(P=0.156)$.

\section{Discussion}

Since the hypothesis linking circadian disruption to increased breast cancer risk was first proposed twenty years ago, there have been many molecular epidemiologic studies implicating the tumorigenic importance of circadian variations, including genetic and epigenetic variations, and aberrant gene expression $[10,57,58]$. TIMELESS, which regulates directly or indirectly the activity of autoregulatory components of the mammalian circadian core, has been shown to play an essential role in the cell cycle checkpoint response $[8,9]$. As a potential molecular bridge between the cell cycle and the circadian regulatory systems, TIMELESS is also likely to play a significant role in tumorigenesis.

In our previous breast cancer case-control study, we found significant associations between two tagging SNPs in the TIMELESS gene and decreased breast cancer susceptibility. TIMELESS promoter hypomethylation in peripheral blood lymphocytes was also found to be significantly associated with later-stage breast cancer. In the current study, we observed that TIMELESS is frequently overexpressed in tumor relative to normal tissues in several cancer types, and that elevated expression of TIMELESS is significantly associated with later tumor stages and poorer breast cancer prognosis. Our findings also provide the first evidence suggesting the diagnostic and prognostic potential of TIMELESS in cancer.

Intriguingly, all 26 genes in the top IPA-generated network have been reported to be involved in cancer. G0S2 (3.37-fold increase), which encodes a mitochondrial protein that specifically interacts with $\mathrm{Bcl}-2$, is a proapoptotic factor, and its ectopic expression induces apoptosis in diverse human cancer cell lines in which endogenous GOS2 is normally epigenetically silenced [48]. Similarly, RhoB (2.16-fold increase) is a well-characterized small GTPase that can inhibit cell proliferation, survival and invasion, and it is often down-regulated in cancer cells [47]. EMP1 (5.33-fold increase) encodes a potential tumor suppressor that is associated with cellular proliferation and metastasis [49]. DMBT1 (Deleted in malignant brain tumors 1 protein) (5.26-fold decrease) is a putative tumor suppressor gene frequently deleted in brain, gastrointestinal and lung cancers and down-regulated in breast cancer and prostate cancer [59]. Interestingly, Superoxide dismutase (SOD2), a probable tumor suppressor responsible for the destruction of superoxide free radicals [44], displayed a 15.9-fold increase in expression following TIMELESS knockdown. Additionally, Endothelin-1 (EDN1) (4.26-fold increase) encodes a growth factor that is frequently produced by cancer cells and plays a key role in cell growth, differentiation, apoptosis, and tumorigenesis [27]. Bone Morphogenetic protein 7 (BMP7) (2.41-fold increase), also known as osteogenic protein 1 (OP-1), encodes a multifunctional growth factor belonging to the TGF- $\beta$ superfamily. Elevated BMP7 levels are reported to be correlated with the depth of colorectal tumor invasion, liver metastasis and cancer-related death [60], as well as the levels of estrogen and progesterone receptor, both of which are important markers for breast cancer prognosis and therapy [61]. Similarly, GDF15 (4.49-fold increase), which encodes another member of the TGF- $\beta$ superfamily, was reported to exert proapoptotic and anti-tumorigenic functions on colorectal, prostate, and breast cancer cells in vitro and on colon and blioblastoma tumors in vivo [62]. IL8 (5.1-fold increase) has also been reported to have functions in the regulation of 

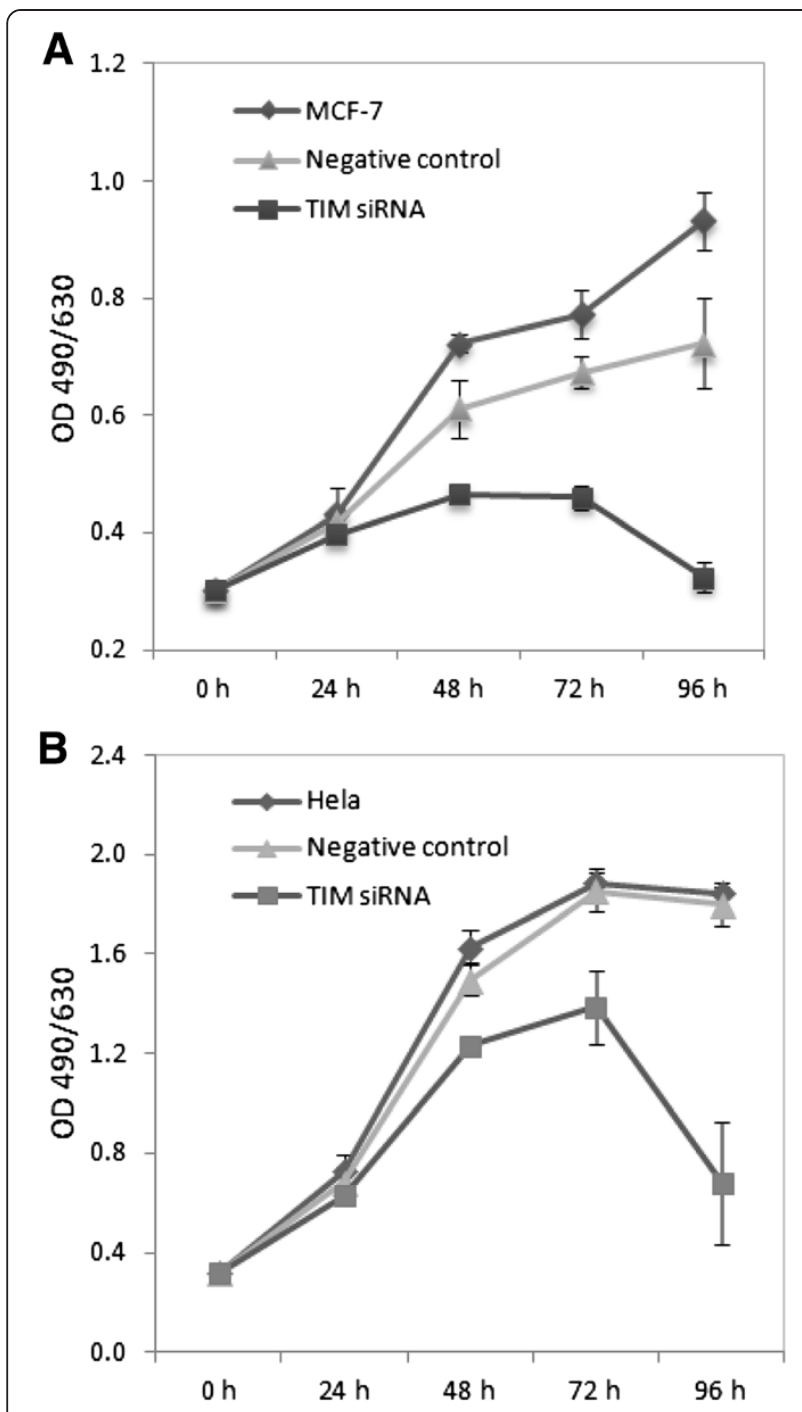

Figure 4 MCF7 and HeLa cell proliferation rates were assessed at baseline, 24 hours, 48 hours, 72 hours, and 96 hours following transfection with a TIMELESS siRNA and a scrambled sequence negative control oligo. (A) Transfection with TIMELESS siRNA in MCF7 cells slowed down cell proliferation compared to negative controls $(P<0.05)$; (B) TIMELESS knockdown did not result in a significant reduction in cell proliferation rate in HeLa cells. Error bars represent standard deviations.

angiogenesis, cell growth and survival, leukocyte infiltration, and modification of immune responses [63]. These data suggest that loss of TIMELESS expression has the potential to influence a set of cancer-relevant genes, although most of these genes showing altered expression may not interact directly with TIMELESS. However, without further mechanistic investigations, it is not possible to identify whether these transcripts are direct or indirect targets of TIMELESS.

Timeless, together with its constitutive binding partner, Tipin, functions as a replisome-associated protein which interacts with components of the endogenous replication fork complex [64]. Moreover, siRNA-mediated TIMELESS down-regulation attenuates DNA replication efficiency [64]. Consistent with this observation, we observed a significant decrease in MCF7 cell proliferation after TIMELESS knockdown. However, we found only a slight but non-significant decrease in cell proliferation in HeLa cells following TIMELESS knockdown. This latter observation is consistent with the finding that TIMELESS down-regulation did not have a significant effect on cell proliferation in HeLa cells previously reported by Masai et al. [65]. As a recent study conducted by Engelen et al. revealed elevated TIMELESS expression in tissues undergoing active proliferation, the implication is that increased TIMELESS expression may be a characteristic of all highly proliferative cells, rather than one exclusive to cancer tissues. However, this relationship does not necessarily diminish the significance of TIMELESS in cancer simply because heightened cellular proliferation can be an important driver of the cancerous state. Even if TIMELESS expression is elevated as a result of, rather than a precursor to, heightened proliferation, TIMELESS expression may represent a natural response to abnormal proliferative rates and its potential physiological significance in cancer cannot be discounted. Further mechanistic studies are needed to investigate the precise role of TIMELESS on cellular growth and proliferation in different cancer types, as well as the capacity of TIMELESS to influence other potentially cancer-relevant pathways, including cell motility, invasiveness, and DNA damage response.

Although initial screening found a similar anti-proliferative response to a second siRNA, only the siRNA that conferred the greater phenotypic effect was chosen for subsequent assays. Given the inherent difficulty in controlling for offtarget effects in any knockdown experiment performed using a single siRNA, the results presented here should be subjected to independent validation with use of a second siRNA. Furthermore, there is evidence to suggest that the anti-proliferative response observed from TIMELESS silencing could be partly attributable to apoptosis. It is evident that proliferation of transfected cells plateaus between the 48 hour and 72 hour time points and decreases thereafter, marking a period of gradual cell death. The degree to which silencing of TIMELESS elicits an apoptotic response should be the subject of a future investigation.

\section{Conclusions}

In summary, these findings, although preliminary, support the findings from our previous breast cancer case-control study, and provide further evidence of the link between TIMELESS and carcinogenesis. The expression profiling analysis of the tissue-specific microarray data suggests that TIMELESS is frequently overexpressed in various types of tumor tissues, and elevated TIMELESS expression is associated with advanced tumor stage and poorer breast cancer 
prognosis. These data, in conjunction with the findings from the network analysis and the cell proliferation assay, suggest TIMELESS may be involved in the tumorigenic process. However, further mechanistic investigations are warranted to further elucidate the precise role of TIMELESS in tumorigenesis, and to help in the development of targeted therapeutic strategies.

\section{Additional files}

Additional file 1: Table S1. Sequences of primers used for quantitative real-time PCR. Table S2: Details of the 32 analyses of TIMELESS expression in tumor compared to normal tissues when filtered by $P$-value $<0.01$ and fold change $\geq|2|$ (Oncomine). Table S3: Details of the networks identified by the IPA software as significantly associated with the transcripts differentially expressed following TIMELESS knockdown.

Additional file 2: Figure S1. TIMELESS knockdown confirmation in two biological duplicate populations of HeLa cells by real-time qPCR. Figure S2: Real-time qPCR confirmation of selected genes with differential expression following TIMELESS knockdown detected by the microarray analysis.

\section{Competing interest}

The authors declare that they have no competing interest.

\section{Authors' contributions}

YYM was responsible for performing database searches, analyzing microarray data, carrying out cell proliferation assays, and preparing the first manuscript draft. AF carried out the initial cell culture experiments and aided in manuscript preparation. DL helped to optimize conditions required for TIMELESS knockdown. YZ aided in experimental design and manuscript preparation. TZ and KC helped with manuscript preparation. All authors have read and approved the final manuscript.

\section{Acknowledgments}

This work was supported by the National Institutes of Health grant (grants ES018915 and CA122676). Yingying's visit at Yale University was supported by the China Scholarship Council (CSC).

\section{Author details}

'Department of Epidemiology and Health Statistics, Zhejiang University School of Public Health, Hangzhou, Zhejiang Province, China. '2Department of Environmental Health Sciences, Yale School of Public Health, New Haven, CT 06520, USA.

Received: 28 May 2013 Accepted: 4 October 2013

Published: 25 October 2013

\section{References}

1. Young MW, Kay SA: Time zones: a comparative genetics of circadian clocks. Nat Rev Genet 2001, 2:702-715.

2. Ko CH, Takahashi JS: Molecular components of the mammalian circadian clock. Hum Mol Genet 2006, 15(2):R271-R277.

3. Sclafani RA, Holzen TM: Cell cycle regulation of DNA replication. Annu Rev Genet 2007, 41:237-280.

4. Sancar A, Lindsey-Boltz LA, Unsal-Kacmaz K, Linn S: Molecular mechanisms of mammalian DNA repair and the DNA damage checkpoints. Annu Rev Biochem 2004, 73:39-85.

5. Levi F, Filipski E, lurisci I, Li XM, Innominato P: Cross-talks between circadian timing system and cell division cycle determine cancer biology and therapeutics. Cold Spring Harb Symp Quant Biol 2007, 72:465-475.

6. Bjarnason GA, Jordan R: Circadian variation of cell proliferation and cell cycle protein expression in man: clinical implications. Prog Cell Cycle Res 2000, 4:193-206.

7. Unsal-Kacmaz K, Mullen TE, Kaufmann WK, Sancar A: Coupling of human circadian and cell cycles by the timeless protein. Mol Cell Biol 2005, 25:3109-3116
8. Dheekollu J, Wiedmer A, Hayden J, Speicher D, Gotter AL, Yen T, Lieberman PM: Timeless links replication termination to mitotic kinase activation. PLoS One 2011, 6:e19596.

9. Yang XM, Wood PA, Hrushesky WJM: Mammalian TIMELESS Is Required for ATM-dependent CHK2 Activation and G(2)/M Checkpoint Control. J Biol Chem 2010, 285:3030-3034.

10. Stevens RG: Circadian disruption and breast cancer: from melatonin to clock genes. Epidemiology 2005, 16:254-258.

11. Stevens RG, Rea MS: Light in the built environment: potential role of circadian disruption in endocrine disruption and breast cancer. Canc Causes Control 2001, 12:279-287.

12. Hanahan D, Weinberg RA: The hallmarks of cancer. Cell 2000, 100:57-70.

13. Fu A, Leaderer D, Zheng T, Hoffman AE, Stevens RG, Zhu Y: Genetic and epigenetic associations of circadian gene TIMELESS and breast cancer risk. Mol Carcinog 2011, 51(12):923-929.

14. Mazzoccoli G, Panza A, Valvano MR, Palumbo O, Carella M, Pazienza V, Biscaglia G, Tavano F, Di Sebastiano P, Andriulli A, Piepoli A: Clock gene expression levels and relationship with clinical and pathological features in colorectal cancer patients. Chronobiol Int 2011, 28:841-851.

15. Lin YM, Chang JH, Yeh KT, Yang MY, Liu TC, Lin SF, Su WW, Chang JG: Disturbance of circadian gene expression in hepatocellular carcinoma. Mol Carcinog 2008, 47:925-933.

16. Rhodes DR, Yu J, Shanker K, Deshpande N, Varambally R, Ghosh D, Barrette T, Pandey A, Chinnaiyan AM: ONCOMINE: a cancer microarray database and integrated data-mining platform. Neoplasia 2004, 6:1-6.

17. Fischer-Doetzkies $E$, Georg J: [Shift-work management in nursing]. Pflege Aktuell 2005, 59:72-75.

18. Zhai Y, Kuick R, Nan B, Ota I, Weiss SJ, Trimble CL, Fearon ER, Cho KR: Gene expression analysis of preinvasive and invasive cervical squamous cell carcinomas identifies HOXC10 as a key mediator of invasion. Canc Res 2007, 67:10163-10172.

19. Cheng AS, Culhane AC, Chan MW, Venkataramu CR, Ehrich M, Nasir A, Rodriguez BA, Liu J, Yan PS, Quackenbush J, et al: Epithelial progeny of estrogen-exposed breast progenitor cells display a cancer-like methylome. Canc Res 2008, 68:1786-1796.

20. Sreekumar A, Poisson LM, Rajendiran TM, Khan AP, Cao Q, Yu J, Laxman B, Mehra R, Lonigro RJ, Li Y, et al: Metabolomic profiles delineate potential role for sarcosine in prostate cancer progression. Nature 2009, 457:910-914.

21. Taylor BS, Schultz N, Hieronymus H, Gopalan A, Xiao Y, Carver BS, Arora VK, Kaushik $P$, Cerami E, Reva B, et al: Integrative genomic profiling of human prostate cancer. Canc Cell 2010, 18:11-22.

22. Carroll JS, Meyer CA, Song J, Li W, Geistlinger TR, Eeckhoute J, Brodsky AS, Keeton EK, Fertuck KC, Hall GF, et al: Genome-wide analysis of estrogen receptor binding sites. Nat Genet 2006, 38:1289-1297.

23. Ringner M, Fredlund E, Hakkinen J, Borg A, Staaf J: GOBO: gene expression-based outcome for breast cancer online. PLOS One 2011, 6:e17911.

24. Calvano SE, Xiao W, Richards DR, Felciano RM, Baker HV, Cho RJ, Chen RO, Brownstein BH, Cobb JP, Tschoeke SK, et al: A network-based analysis of systemic inflammation in humans. Nature 2005, 437:1032-1037.

25. Benjamini $Y$, Hochberg $Y$ : Controlling the false discovery rate - a practical and powerful approach to multiple testing. J Roy Stat Soc Ser B Meth 1995, 57:289-300.

26. Cheng WL, Wang CS, Huang YH, Tsai MM, Liang Y, Lin KH: Overexpression of CXCL1 and its receptor CXCR2 promote tumor invasion in gastric cancer. Ann Oncol 2011, 22:2267-2276.

27. Kim $\mathrm{TH}$, Xiong $\mathrm{H}$, Zhang $\mathrm{Z}$, Ren B: Beta-Catenin activates the growth factor endothelin-1 in colon cancer cells. Oncogene 2005, 24:597-604

28. Bangoura G, Liu ZS, Qian Q, Jiang CQ, Yang GF, Jing S: Prognostic significance of HIF-2alpha/EPAS1 expression in hepatocellular carcinoma. World J Gastroenterol 2007, 13:3176-3182.

29. Mohammed N, Rodriguez M, Garcia V, Garcia JM, Dominguez G, Pena C, Herrera M, Gomez I, Diaz R, Soldevilla B, et al: EPAS1 mRNA in plasma from colorectal cancer patients is associated with poor outcome in advanced stages. Oncol Lett 2011, 2:719-724.

30. Wallin U, Glimelius B, Jirstrom K, Darmanis S, Nong RY, Ponten F, Johansson C, Pahlman L, Birgisson H: Growth differentiation factor 15: a prognostic marker for recurrence in colorectal cancer. Br J Canc 2011, 104:1619-1627. 
31. Staff AC, Trovik J, Eriksson AG, Wik E, Wollert KC, Kempf T, Salvesen HB: Elevated plasma growth differentiation factor-15 correlates with lymph node metastases and poor survival in endometrial cancer. Clin Canc Res 2011, 17:4825-4833.

32. Xie K: Interleukin-8 and human cancer biology. Cytokine Growth Factor Rev 2001, 12:375-391.

33. Benoy $I H$, Salgado R, Van Dam P, Geboers K, Van Marck E, Scharpe $S$, Vermeulen PB, Dirix LY: Increased serum interleukin-8 in patients with early and metastatic breast cancer correlates with early dissemination and survival. Clin Canc Res 2004, 10:7157-7162.

34. Depianto D, Kerns ML, Dlugosz AA, Coulombe PA: Keratin 17 promotes epithelial proliferation and tumor growth by polarizing the immune response in skin. Nat Genet 2010, 42:910-914.

35. Economescu MC, Necula LG, Dragu D, Badea L, Dima SO, Tudor S, Nastase A, Popescu I, Diaconu CC: Identification of potential biomarkers for early and advanced gastric adenocarcinoma detection. Hepatogastroenterology 2010, 57:1453-1464.

36. Kim YH, Kwei KA, Girard L, Salari K, Kao J, Pacyna-Gengelbach M, Wang P, Hernandez-Boussard T, Gazdar AF, Petersen I, et al: Genomic and functional analysis identifies CRKL as an oncogene amplified in lung cancer. Oncogene 2010, 29:1421-1430.

37. Padmanabhan RA, Nirmala L, Murali M, Laloraya M: CrkL is a co-activator of estrogen receptor alpha that enhances tumorigenic potential in cancer. Mol Endocrinol 2011, 25:1499-1512.

38. Baraniskin A, Birkenkamp-Demtroder K, Maghnouj A, Zollner $H$, Munding J, Klein-Scory S, Reinacher-Schick A, Schwarte-Waldhoff I, Schmiegel W, Hahn SA: MiR-30a-5p suppresses tumor growth in colon carcinoma by targeting DTL. Carcinogenesis 2012, 33(4):732-739.

39. Sossey-Alaoui K, Kitamura E, Cowell JK: Fine mapping of the PTGFR gene to $1 \mathrm{p} 31$ region and mutation analysis in human breast cancer. Int J Mol Med 2001, 7:543-546

40. Cho HS, Toyokawa G, Daigo Y, Hayami S, Masuda K, Ikawa N, Yamane Y, Maejima K, Tsunoda T, Field Hl, et al: The JmjC domain-containing histone demethylase $\mathrm{KDM} 3 \mathrm{~A}$ is a positive regulator of the $\mathrm{G}(1) / \mathrm{S}$ transition in cancer cells via transcriptional regulation of the HOXA1 gene. Int J Canc 2011, 131(3):E179-E189.

41. Chevillard S, Ugolin N, Vielh P, Ory K, Levalois C, Elliott D, Clayman GL, El-Naggar AK: Gene expression profiling of differentiated thyroid neoplasms: diagnostic and clinical implications. Clin Canc Res 2004, 10:6586-6597.

42. Riker Al, Enkemann SA, Fodstad O, Liu S, Ren S, Morris C, Xi Y, Howell P, Metge B, Samant RS, et al: The gene expression profiles of primary and metastatic melanoma yields a transition point of tumor progression and metastasis. BMC Med Genom 2008, 1:13.

43. Papatriantafyllou M: Tumour immunology: TSLP drives human tumour progression. Nat Rev Immunol 2011, 11:235.

44. Bravard A, Sabatier L, Hoffschir F, Ricoul M, Luccioni C, Dutrillaux B: SOD2: a new type of tumor-suppressor gene? Int J Canc 1992, 51:476-480.

45. Liu X, Wang A, Lo Muzio L, Kolokythas A, Sheng S, Rubini C, Ye H, Shi F, Yu $T$, Crowe DL, Zhou $X$ : Deregulation of manganese superoxide dismutase (SOD2) expression and lymph node metastasis in tongue squamous cell carcinoma. BMC Canc 2010, 10:365.

46. Zhou J, Zhu Y, Zhang G, Liu N, Sun L, Liu M, Qiu M, Luo D, Tang Q, Liao Z, et al: A distinct role of RhoB in gastric cancer suppression. Int J Canc 2011, 128:1057-1068.

47. Huang M, Prendergast GC: RhoB in cancer suppression. Histol Histopathol 2006, 21:213-218.

48. Welch C, Santra MK, El-Assaad W, Zhu XC, Huber WE, Keys RA, Teodoro JG, Green MR: Identification of a protein, GOS2, that lacks Bcl-2 homology domains and Interacts with and antagonizes Bcl-2. Canc Res 2009, 69:6782-6789

49. Zhang J, Cao W, Xu Q, Chen WT: The expression of EMP1 is downregulated in oral squamous cell carcinoma and possibly associated with tumour metastasis. J Clin Pathol 2011, 64:25-29.

50. Jensen SM, Maston LD, Gough MI, Ruby CE, Redmond WL, Crittenden M, Li YH, Puri S, Poehlein $\mathrm{CH}$, Morris N, et al: Signaling through OX40 enhances antitumor immunity. Semin Oncol 2010, 37:524-532.

51. Buglio D, Khaskhely NM, Voo KS, Martinez-Valdez H, Liu YJ, Younes A: HDAC11 plays an essential role in regulating OX40 ligand expression in Hodgkin lymphoma. Blood 2011, 117:2910-2917.
52. Braidotti $P$, Nuciforo PG, Mollenhauer J, Poustka A, Pellegrini C, Moro A, Bulfamante G, Coggi G, Bosari S, Pietra GG: DMBT1 expression is down-regulated in breast cancer. BMC Canc 2004, 4. http://www. biomedcentral.com/1471-2407/4/46.

53. Du J, Guan M, Fan J, Jiang H: Loss of DMBT1 expression in human prostate cancer and its correlation with clinical progressive features. Urology 2011, 77(509):e509-e513.

54. Cho YG, Chang X, Park IS, Yamashita K, Shao C, Ha PK, Pai SI, Sidransky D, Kim MS: Promoter methylation of leukemia inhibitory factor receptor gene in colorectal carcinoma. Int J Oncol 2011, 39:337-344.

55. Ribarska T, Ingenwerth M, Goering W, Engers R, Schulz WA: Epigenetic inactivation of the placentally imprinted tumor suppressor gene TFPI2 in prostate carcinoma. Canc Genom Proteomics 2010, 7:51-60.

56. Fox BP, Kandpal RP: EphB6 receptor significantly alters invasiveness and other phenotypic characteristics of human breast carcinoma cells. Oncogene 2009, 28:1706-1713.

57. Hoffman $A E$, Zheng $T$, Stevens RG, Ba Y, Zhang $Y$, Leaderer $D, Y i C$, Holford TR, Zhu Y: Clock-cancer connection in non-Hodgkin's lymphoma: a genetic association study and pathway analysis of the circadian gene cryptochrome 2. Canc Res 2009, 69:3605-3613.

58. Hoffman $A E, Y i C H$, Zheng $T$, Stevens RG, Leaderer D, Zhang Y, Holford TR, Hansen J, Paulson J, Zhu Y: CLOCK in breast tumorigenesis: genetic, epigenetic, and transcriptional profiling analyses. Canc Res 2010, 70:1459-1468.

59. Mollenhauer J, Herbertz S, Holmskov U, Tolnay M, Krebs I, Merlo A, Schroder HD, Maier D, Breitling F, Wiemann S, et al: DMBT1 encodes a protein involved in the immune defense and in epithelial differentiation and is highly unstable in cancer. Canc Res 2000, 60:1704-1710.

60. Motoyama K, Tanaka F, Kosaka Y, Mimori K, Uetake H, Inoue H, Sugihara K, Mori M: Clinical significance of BMP7 in human colorectal cancer. Ann Surg Oncol 2008, 15:1530-1537.

61. Schwalbe M, Sanger J, Eggers R, Naumann A, Schmidt A, Hoffken K, Clement $J \mathrm{H}$ : Differential expression and regulation of bone morphogenetic protein 7 in breast cancer. Int J Oncol 2003, 23:89-95.

62. Strelau J, Schmeer C, Peterziel H, Sackmann T, Herold-Mende C, Steiner H, Weller $\mathrm{M}$, Unsicker $\mathrm{K}$ : Expression and putative functions of GDF-15, a member of the TGF-beta superfamily, in human glioma and glioblastoma cell lines. Canc Lett 2008, 270:30-39.

63. Yuan A, Chen JJ, Yao PL, Yang PC: The role of interleukin-8 in cancer cells and microenvironment interaction. Front Biosci 2005, 10:853-865.

64. Gotter AL, Suppa C, Emanuel BS: Mammalian TIMELESS and Tipin are evolutionarily conserved replication fork-associated factors. J Mol Biol 2007, 366:36-52.

65. Yoshizawa-Sugata N, Masai H: Human Tim/Timeless-interacting protein, Tipin, is required for efficient progression of $\mathrm{S}$ phase and DNA replication checkpoint. J Biol Chem 2007, 282:2729-2740.

doi:10.1186/1471-2407-13-498

Cite this article as: Mao et al:: Potential cancer-related role of circadian gene TIMELESS suggested by expression profiling and in vitro analyses. BMC Cancer 2013 13:498.

\section{Submit your next manuscript to BioMed Central and take full advantage of:}

- Convenient online submission

- Thorough peer review

- No space constraints or color figure charges

- Immediate publication on acceptance

- Inclusion in PubMed, CAS, Scopus and Google Scholar

- Research which is freely available for redistribution 